\title{
O vírus neoliberal no Brasil e a polêmica com Giorgio Agamben
}

\author{
The neoliberal virus in Brazil and the controversy with Giorgio Agamben
}

\section{Ricardo Evandro Santos Martins*}

Resumo: Exploro os conceitos de campo e de estado de exceção e tento mostrar como Giorgio Agamben, por um lado, é coerente com sua obra, além de estar certo no diagnóstico do presente, mas, por outro, exagera na desconfianca da real mortalidade do Coronavírus e, também, como este posicionamento do filósofo italiano não serve à experiência brasileira, especialmente quanto à problemática de uma aparente concordância do ministro Araújo do Governo Bolsonaro com seu alerta para o estado de excecão permanente.

Palavras-chave: Giorgio Agamben; Coronavírus; Pandemia; Estado de Exceção; Ernesto Araújo; Biopolítica

Abstract: I explore the concepts of field and state of exception and try to show how Giorgio
Agamben, on the one hand, is coherent with his work, besides being right in the diagnosis of
the present, but, on the other hand, exaggerates the distrust of the real mortality of
Coronavirus and, also, how this position of the Italian philosopher does not serve the
Brazilian experience, especially regarding the problem of an apparent agreement of the
Minister Araújo with the president, Jair Messias Bolsonaro, with his alert for the state of
permanent exception. Keywords: Giorgio Agamben; Coronavirus; Pandemic; Estate of exception; Ernesto Araújo; Biopolitics

\section{Introdução}

No dia 7 de fevereiro de 1979, em Bertioga, pequena cidade litorânea do Estado de São Paulo, no Brasil, foi encontrado morto o corpo do austríaco Wolfgang Gerhard. Era um homem alto, branco, de bigode, que tinha sinais de afogamento. Mas somente no ano de 1985 é que se descobriu que este homem não se tratava de um imigrante austríaco. O seu verdadeiro nome era Josef Mengele, também conhecido como "O Anjo da Morte". Mengele era capitão da SS e o médico que trabalhava no campo de concentração de Auschwitz. Ele ficou famoso pelos experimentos que realizava, especialmente em irmãos gêmeos cativos no campo, além de cirurgias experimentais sem o uso de anestesia. Mengele viveu no Brasil por 35 anos, usando diversos nomes falsos. Ele tinha morado em outra cidade no Brasil, de nome curioso, Nova Europa, e somente no final de sua vida é que foi morar num lugar mais afastado, devido ao seu medo paranoico de ser capturado pela polícia de Israel, como havia ocorrido, anos antes, também na América Latina, com outro nazista famoso, Adolf Eichmann.

Trouxe esses fatos para lembrar que, mais do que a participação brasileira na II Guerra, ao lado dos Aliados, e, antes ainda, mais do que as expedições nazistas na Amazônia brasileira nos anos 30 em minha cidade, Belém do Pará, o nazismo intercruza a história recente do Brasil também nesse episódio, quando um dos mais nefastos cientistas nazistas escondeu-se das possíveis consequências dos seus crimes de guerra no meu país. Eu recordei

${ }^{1}$ POSNER; WARE, Mengele: A História completa do Anjo da Morte de Auschwitz, p. 66

Docente no Programa de Pós-Graduação em Direito da Universidade Federal do Pará, Belém, PA. E-mail: ricardoevandromartins@gmail.com ORCID: https://orcid.org/oooo-0001-8648-1260 
desse fato no momento em que terminei de ler o artigo do atual ministro da Relações Exteriores do Brasil, o chanceler Ernesto Araújo, quando publicou, no dia 22 de abril deste ano, em seu blog pessoal, o artigo intitulado de Chegou o Comunavirus, em que cita 2 filósofos contemporâneos importantes para o debate da esquerda, Slavoj Zizek e Giorgio Agamben. Ambos os filósofos têm se pronunciado muito sobre as possíveis implicações políticas da atual pandemia do Coronavírus COVID-19, ou SARS-CoV-2, que se manifestou no final do ano de 2019, na província de Wuhan, China. Araújo os citou para fundamentar seu recente artigo que, dentre algumas teses, acredita que a atual pandemia poderia ensejar um movimento político contra a democracia liberal, justificando, portanto, o uso de medidas excepcionais semelhantes às de um estado nazista.

No artigo, o chanceler brasileiro Ernesto Araújo basicamente tenta argumentar que: o surgimento do "Coronavírus [COVID-19] nos faz despertar novamente para o pesadelo do comunismo"; e que isto é mostrado pelo filósofo esloveno Slavoj Zizek, quando no seu recente livro sobre a pandemia, Virus (2020), "revela aquilo que os marxistas há trinta anos escondem: o globalismo substitui o socialismo como estágio preparatório ao comunismo."; "que entrega sem disfarce o jogo comunista-globalista de apropriação da pandemia para subverter completamente a democracia liberal e a economia de mercado"; e cita Agamben, como sendo "filósofo de esquerda aparentemente não-marxista, que escreveu com grande apreensão sobre o cerceamento de liberdades que está em curso", e que, em vez de também ver com preocupação tal suposto risco para as liberdades individuais, como o filósofo italiano o faz, Zizek "recebe [o] com júbilo"; assim, "[a] pretexto da pandemia, o novo comunismo trata de construir um mundo sem nações, sem liberdade (...)"; e também construir " [u]m estado de exceção global permanente, transformando o mundo num grande campo de concentração" ${ }^{2}$.

A partir dessas passagens que destaquei do artigo de Araújo, neste ensaio tenho como objetivos principais interpretar a passagem em que Araújo se utiliza do posicionamento de Agamben porque, ainda que tenha se concentrado no livro de Zizek, de modo distinto ao texto do ministro das relações exteriores do Brasil, neste ensaio, pretendo levantar a problemática em torno do posicionamento de Agamben em seus recentes textos sobre a pandemia. Minhas hipóteses são: a) de que a posição de Agamben sobre como as medidas de isolamento social podem gerar um estado de exceção permanente não se adequa na sua totalidade ao contexto da experiência brasileira com a atual pandemia; b) além disto, como mostrei com as passagens do texto de Araújo, defendo que a posição de Agamben foi instrumentalizada pelo ministro como justificativa para as declarações e negligências do atual governo federal brasileiro, presidido pelo ex-Capitão do Exército, Jair Messias Bolsonaro, quem, contrariamente às medidas pela imposição de lockdown por alguns governadores estaduais no Brasil, tem considerado a atual pandemia um caso menor, um surto de uma "gripezinha", que quer levar a economia interna brasileira à depressão, causando desemprego e fechamento de empresas, pequenos negócios e indústrias.

\section{A polêmica com Giorgio Agamben}

Desde fevereiro deste ano até o momento em que escrevo este ensaio, no espaço eletrônico que possui no site quidlibet.it, na sessão Una voce di Giorgio Agamben, Agamben publicou um total de 9 artigos, curtos e mais longos, sobre a pandemia do COVID-19. Logo no primeiro artigo, denominado de $A$ invenção de uma pandemia, de 20 de fevereiro de 2020 ,

${ }^{2}$ ARAÚJO, Chegou o Comunvírus. Metapolítica 17. 22.abr.2020. 
Agamben causa polêmica ao chamar as medidas do governo da Itália sobre o início de contágio na época de "medidas de emergência frenéticas, irracionais, e completamente injustificadas". Agamben questionou o motivo pelo qual a mídia e as autoridades estariam "trabalhando para espalhar um clima de pânico, causando um verdadeiro estado de exceção, com sérias limitações de movimentos e uma suspensão do funcionamento normal das condições de vida e de trabalho em regiões inteiras?". Baseado na posição do CNR (Consiglio Nazionale delle Ricerche) - Conselho Nacional de Pesquisa da Itália -, Agamben viu uma desproporcionalidade no tratamento da gripe que, até então, parecia uma "gripe normal". Para o filósofo, "[p]arece que, tendo esgotado o terrorismo como causa de medidas excepcionais, a invenção de uma epidemia pode oferecer o pretexto ideal para estendê-las além de todos os limites."3.

A partir desse texto, que trouxe outras afirmações também polêmicas quanto ao medo excessivo instaurado devido ao Coronavírus, Agamben foi atacado por diversos colegas seus, como Jean-Luc Nancy, Roberto Esposito, etc. Desde então passou a publicar outros textos e a dar entrevistas, ora tentando justificar sua posição no seu primeiro texto de fevereiro, ora confirmando o seu alerta para as medidas de exceção que poderiam surgir, impedido um retorno à normalidade. Na sua penúltima manifestação sobre o tema, do dia 22 de abril deste ano, dada em entrevista, ao ser perguntado se "[e]stamos vivendo, com esta reclusão forçada, um novo totalitarismo?", Agamben diz que “[d]e muitos lados estamos agora formulando a hipótese de que estamos realmente vivendo o fim de um mundo, o das democracias burguesas, baseadas em direitos, parlamentos e divisão de poderes, que está dando lugar a um novo despotismo"4.

Assim, resta-me dar continuidade aos objetivos deste ensaio e prosseguir com a problematização do posicionamento de Agamben, mostrando como seus textos sobre a pandemia são, por um lado, muito coerentes com suas categorias ontológico-políticas, capazes de compreender o presente, a atualidade, mas que, por outro lado, no nosso caso brasileiro, é preciso ir além e mostrar que as medidas pelo isolamento social são acertadas, a despeito do que declara o presidente brasileiro de extrema-direita e seu ministro das relações exteriores. E, para isto, preciso me lançar a 3 tarefas: a primeira é a de explorar melhor as categorias de Agamben que fundamentam seu posicionamento crítico às medidas governamentais de exceção; a segunda tarefa é de mostrar o porquê destas medidas serem necessárias no Brasil na luta contra a pandemia; e a terceira é a de desvelar o verdadeiro autoritarismo e o funcionamento da máquina de política de morte ao fundo do discurso somente aparentemente liberal, contrário à rigidez do dever da população estar em quarentena até que ao menos o pico do contágio regrida.

Muito antes de Agamben, na aula de 15 de janeiro de 1975, organizada no livro Os anormais (1975), Michel Foucault já falava sobre como a peste, durante a Idade Média, foi o momento em que, apesar das muitas abordagens sobre o tema, com "toda uma espécie de sonho orgiástico, da peste, em que a peste é o momento em que as individualidades se desfazem, em que a lei é esquecida", foi também o momento em que houve outro sonho: "um sonho político da peste, em que esta é, ao contrário, o momento maravilhoso em que o poder político se exerce plenamente". Segundo Foucault, "o momento da peste é o momento do policiamento exaustivo de uma população por um poder político, cujas ramificações capilares atingem sem cessar o próprio grão dos indivíduos, seu tempo, seu habitat, sua localização, seu corpo" ${ }^{5}$. Como se vê, Agamben segue Foucault ao ler a atual pandemia como

\footnotetext{
3 AGAMBEN, Sul vero e sul falso. Quodlibet, 22.abr.202ob.

${ }^{4}$ AGAMBEN, L’invenzione di un'epidemia, Quodlibet, 22.fev.2020a.

${ }^{5}$ FOUCAULT, Os Anormais, p. 41.
} 
um momento de exaustivo exercício de poder político, ao mesmo tempo que também de suspensão da lei.

Mas, para se entender isso melhor, é preciso trazer aqui um pouco da filosofia éitcopolítica de Agamben, especialmente o modo como o filósofo italiano se apropria de Foucault, inicialmente com o seu História da sexualidade vol. I: A vontade de saber (1976), interpretando-o, dentre muitas outras influências e conceitos, desde os conceitos-limite tratados pelo jurista nazista Carl Schmitt, no seu Teologia política (1922), e pela filósofa judia Hannah Arendt, a partir de As origens do totalitarismo (1951) e de A condição humana (1958): biopolítica, estado de exceção e o campo de concentração. Antes das publicações póstumas dos seminários de Foucault no College de France, Agamben ficou famoso pelo seu projeto de se repensar o agir político com o conjunto de obras reunidas sob o nome de Homo sacer. Assim, aqui, irei me ater apenas aos 2 primeiros volumes do projeto Homo sacer, os quais considero como os mais importantes para se entender as categorias "estado de exceção" e "campo", que são Homo sacer: O poder soberano e a vida nua vol. I (1995) e Estado de exceção vol II,1 (2003).

Publicados em contextos políticos distintos, o primeiro volume, feito no momento da Guerra de Kosovo, e o segundo, feito após o ataque terrorista do 11 de Setembro, durante a Guerra do Iraque, Homo sacer: O poder soberano e a vida nua e Estado de exceção procuram desvelar o nexo entre biopolítica, estado de exceção e campo. De modo resumido, comentando a experiência europeia com os campos de concentração na Alemanha nazista, Agamben diz que "[n]a medida em que os seus habitantes foram despojados de todo estatuo político e reduzidos integralmente a vida nua, o campo é também o mais absoluto espaço biopolítico que jamais tenha sido realizado, no qual o poder não tem diante de si senão a pura vida sem qualquer mediação"6, ou seja, o espaço político normal, com suas garantias de direitos, torna-se o campo onde e quando o espaço em que o sujeito de direitos reduz-se à mera vida, à vida nua, lugar em que a sua inscrição no nómos, na ordem jurídica, é suspensa numa relação de exceção, que abandona a vida ao mesmo tempo que a captura pela sua própria excepcionalidade. Segundo Agamben, "o campo é o próprio paradigma do espaço político no ponto em que a política torna-se biopolítica e o homo sacer se confunde virtualmente com o cidadão"7.

Especificamente quanto ao estado de exceção, Agamben defende que, desde o totalitarismo moderno, "que pode ser definido, nesse sentido, como a instauração, por meio do estado de exceção, de uma guerra civil legal”, em que adversários e categorias inteiras de cidadãos são fisicamente eliminados por não conseguirem ser incluídos no sistema político vigente, "[d]esde então, a criação voluntária de um estado de emergência permanente (ainda que, eventualmente, não declarado nos sentido técnico) tornou-se uma das práticas essências dos Estados contemporâneos, inclusive dos chamados democráticos"9. Como se vê pelas citações, Agamben há tempos tem o diagnóstico sobre o estado de exceção permanente em que vivemos - seguindo a tese de Walter Benjamin em Teses sobre o conceito de história (1940) -, mas articulando tal categoria com a inscrição da "vida nua" na ordem político-jurídica (biopolítica) por meio do Direito, via o poder soberano que se exerce em "relação de exceção", ou seja, numa relação em que "a regra (...), suspendendo-se, dá lugar à exceção e somente deste modo se constitui como regra (...)”. Assim, diz Agamben,

\footnotetext{
${ }^{6}$ AGAMBEN, Homo sacer: O poder soberano e a vida nua, p. 167

7 AGAMBEN, Homo sacer: O poder soberano e a vida nua, p. 167.

${ }^{8}$ AGAMBEN, Estado de exceção, p. 13.

9 AGAMBEN, Estado de exceção, p. 13.
} 
“[c]hamemos relação de exceção a esta forma extrema da relação que inclui alguma coisa unicamente através de sua exclusão"10.

Desse modo, é possível entender melhor o alerta do filósofo italiano para o estado de exceção permanente que pode estar sendo justificado pela crise pandêmica do Coronavírus. E, aqui, o artigo do ministro das relações exteriores do Brasil parece mesmo se afinar com Agamben, quando criticou Zizek e seu suposto entusiasmo com as possíveis consequências políticas que a pandemia pode causar. Araújo e Agamben parecem estar de acordo com relação à potencialidade do estado de exceção, exercido por medidas emergenciais pelos estados-nação, no combate à proliferação rápida do COVID-19. O presidente do Brasil parece também seguir a posição de seu ministro ao discursar em rede nacional pela reabertura do comércio interno nacional e ao criticar as medidas impositivas de isolamento social que alguns governos estaduais brasileiros estão tomando, à revelia do governo federal - como é o caso do meu próprio estado, o Pará, e o estado do Amazonas, ambos situados na Amazônia brasileira, bem como o estado de São Paulo, capital financeira do país. Entretanto, é preciso estar atento à tal situação porque ela pode revelar uma patente contradição entre o que diz o ministro Araújo e seu artigo, conforme explicarei a seguir.

\section{A singularidade do caso brasileiro}

Sobre o caso brasileiro problematizado neste ensaio, relacionando pandemia, Agamben e artigo de Ernesto Araújo, minha hipótese central neste ensaio pode ser resumida do seguinte modo: a aparente preocupação do governo de Bolsonaro, expressa no artigo de seu ministro, não pode ser entendida facilmente como uma posição político-ideológica contrária ao estado de exceção e ao autoritarismo, como se, por acaso, estivessem mesmo em acordo com as teses de Agamben. É preciso ir mais afundo na singularidade política e histórica brasileira. Sobre isto, posso iniciar minha argumentação em favor da hipótese de que: contrariamente do que discursa o governo Bolsonaro, não há temor das restrições das liberdades individuais que poderiam ser causadas pelo isolamento social, enquanto medida excepcional tomada pelos governos estaduais brasileiro, nem há temor de uma real ameaça comunista, que implementaria no Brasil uma ditadura; o que se teme é tão-somente a inviabilização do capitalismo na sua versão neoliberal, e, mais especificamente, do modo de governo neoliberal que Bolsonaro tenta exercer.

O que mais se teme com o isolamento social no Brasil é o déficit econômico grave, que pode nos levar à depressão econômica. Isto aparentemente poderia ser uma preocupação legítima, pois uma grave crise econômica geraria certamente impactos sociais terríveis na vida dos brasileiros. Contudo, é preciso destacar, aqui, que não é esta a maior preocupação do atual governo federal brasileiro. Em verdade, hoje, na elaboração deste ensaio, no final do mês de abril de 2020, mesmo com a grave subnotificação, o número de mortes notificadas já superou o número chinês, onde a pandemia se iniciou. E isto se dá sem ainda o Brasil ter chegado no pico da curva de contágio. Trago estes dados para mostrar que no cálculo da agenda neoliberal de Bolsonaro o isolamento social poderá ser muito pior do que o número alto de mortes por Coronavírus. O que quero dizer é que a defesa pelo relaxamento do isolamento social da população brasileira não tem como objetivo principal a retomada do direito de liberdade, pois o objetivo é não se ter mais prejuízos para a balança comercial e para o PIB deste ano.

${ }^{10}$ AGAMBEN, Homo sacer: O poder soberano e a vida nua, p. 25. 
Sobre isto, preciso lembrar que, na aula de 7 de fevereiro de 1979, reunida no Nascimento da Biopolítica, Foucault nos oferece uma concepção deste tipo de liberalismo, quando ensina que houve uma inversão do propósito original do liberalismo clássico e keynesiano, pois, agora, o que se tem é a necessidade de se "afirmar a liberdade de mercado como princípio organizador e regulador do Estado (...) [o]u seja, um Estado sob vigilância do mercado e não um mercado sob vigilância do Estado"11. Essa definição ajuda muito a entender o real plano político de ação do governo Bolsonaro sobre as vidas no território brasileiro: não é a ciência, tampouco a OMS quem devem fazer a diretrizes da crise pandêmica em que estamos vivendo agora no Brasil, mas sim os clamores do mercado e de sua nova razão governamental, a razão neoliberal, de origem austríaca (Hayek) e norteamericana (Chicago boys) de se manter o consumo alto e a livre atividade do homo oeconomicus. É relativamente simples de se concordar com esta hipótese, quando se lembra que o governo Bolsonaro é composto na sua grande parte por militares, que têm como líder político um capitão do Exército Brasileiro, que sempre fez questão de expor seu amor pela Ditadura civil-militar brasileira, que, por meio de dispositivos excepcionais - dentre eles a normalidade de práticas de torturas em quartéis, delegacias - governou o Brasil entre 1964 e 1985.

É preciso dizer, contudo, que Agamben não está errado: há sim o risco iminente de que governos eleitos democraticamente assumam medidas excepcionais, abusando de seus poderes de emergência e, o pior, não retrocedendo ao fim da pandemia. Mas o que Agamben talvez não saiba é, quanto a nós, no Brasil, pela nossa experiência republicana, o risco de um golpe nas nossas experiências democráticas nada tem de excepcional. Sabemos muito bem deste risco, pois basta que se lembre de como a República do Brasil fundou-se, no final do século XIX, com uma revolução militar, liberal e positivista, e que tem, desde seu início até hoje, um longo histórico de governos realizados por meio de decretos-lei ou de, até mesmo, golpes militares ${ }^{12}$ com a coincidente justificativa do temor de uma revolução comunista - tal temor justificou os golpes de 1937 e de 1964. Por outro lado, é preciso dizer que o Brasil, assim como parte da América Latina, como foi o caso da ditadura chilena com o General Augusto Pinochet, traz consigo um nexo não tão velado entre autoritarismo e neoliberalismo. E, para além das meras declarações, a contradição de Araújo em seu texto pode estar presente no momento em que, ao mesmo tempo em que escreve sobre o perigo da chegada do "comunavírus" e o perigo das medidas totalitárias que Zizek estaria supostamente defendendo, o seu chefe, o presidente Bolsonaro, incorre em fazer o Brasil sofre outro perigo, que é o de se beneficiar do Projeto de Emenda à Constituição Brasileira, a chamada curiosamente por "PEC do Orçamento de Guerra", que poderá dar mais prerrogativas no uso do dinheiro público pelo Banco Central, controlado pelo presidente, em favor de empresas e bancos privados, sem a preocupação de se limitar às leis de responsabilidade fiscal, quando aplicadas em normalidade.

Assim, é possível perceber como a posição de Agamben talvez não dê conta da singularidade do caso brasileiro e do modo como o governo atual de Jair Bolsonaro lida com a crise pandêmica. Portanto, o artigo de Ernesto Araújo se utiliza muito mal do posicionamento de Agamben, independentemente dos problemas que seus textos podem ter em ler a situação de seu próprio país, a Itália. Mas agora é hora de retomar a estória do início deste ensaio. Quero encerra-lo, lembrando que, do mesmo modo que o nazista Josef Mengele se disfarçara, pela última vez, de seu amigo austríaco, tendo morrido como se o seu amigo fosse, os discursos autoritários e o "deixar morrer" do governo Bolsonaro se disfarçam

${ }^{11}$ FOUCAULT, Nascimento da Biopolítica, p. 154-155.

${ }^{12}$ GOMES; MATOS, O estado de exceção no Brasil republicano. 
de ideologia neoliberal, que só aparentemente está interessada na defesa das liberdades individuais dos cidadãos brasileiros nesta crise do Coronavírus. Por isto, quanto ao Agamben, suas categorias foram injustamente instrumentalizadas pelo artigo do ministro Ernesto Araújo, talvez usadas como um recurso de prestidigitação daquilo que realmente pratica seu presidente que o nomeou ao cargo de ministro, seja por suas declarações apologistas à última Ditadura civil-militar brasileira (1964-1985), seja pelo exercício de soberania e de tanatopolítica, de deixar morrer a população por cálculo político favorável, quando, por exemplo, preocupa-se muito mais com a economia do país, com o seu PIB, do que em assistir estados brasileiros em plena calamidade pública como o do Amazonas, no norte do Brasil.

\section{Considerações finais}

Se me for permitido realizar uma comparação - talvez grosseira, quando comparada com a elegância dos textos de Walter Benjamin -, enquanto Agamben desconfia dos dados de mortes na Itália, bem como desconfia da ciência quando se intromete em assuntos éticos e políticos, tendo, a ciência, tornado-se cada vez mais uma "nova religião"13 o erudito filósofo italiano, com muita razão - haja vista a experiência europeia com a Shoah -, parece temer nesta pandemia muito mais a ciência, que sempre corre o risco de ser tanatoplítica, como foi a ciência do "O Anjo da Morte". Enquanto que, nós, brasileiros, para além deste médicomonstro, ou com ele e mais ainda, devido à nossa condição de ex-colônia - experiência de barbárie em meio aos monumentos civilizacionais europeus da Modernidade -, parece que tememos mais o vendaval que arrasta o "Anjo da História” “(...) para o futuro a que ele volta as costas, enquanto o monte de ruínas à sua frente cresce até o céu"14.

Por fim, diria, que, no caso brasileiro, localizado na periferia do capitalismo e da Modernidade, entre estas ruínas do progresso estão os corpos empilhados sem velório na cidade de Manaus, mortos por Coronavírus, enterrados talvez em cima dos corpos indígenas e pretos, mortos pela colonização, pela ditadura, e, hoje, pelo neoliberalismo que invade as reservas tradicionais indígenas e quilombolas.

\section{Agradecimentos}

Gostaria de agradecer aos amigos que me incentivaram e contribuíram a elaborar algumas teses neste ensaio, mesmo que não saibam disso: Evandro Brito, Ernani Chaves, Luiz Alberto Rocha, Maurício Borba Filho, Saulo de Matos e Ricardo Dib Taxi.

\section{Referências}

AGAMBEN, Giorgio. Sul vero e sul falso. Quodlibet, 22.abr.2020. Disponível em: https://www.quodlibet.it/giorgio-agamben-sul-vero-e-sul-falso Consultado em: 30.abr.2020a

AGAMBEN, Giorgio. L'invenzione di un'epidemia, Quodlibet, 22.fev.2020. Disponível em: https://www.quodlibet.it/giorgio-agamben-l-invenzione-di-un-epidemia. Consultado em 30.abr.202ob.

13 AGAMBEN, L'invenzione di un'epidemia, Quodlibet, 22.fev.2020. Disponível em: https://www.quodlibet.it/giorgio-agamben-l-invenzione-di-un-epidemia. Consultado em 30.abr.2O2ob 14 BENJAMIN, Sobre o conceito de História, p. 14. 
8| O vírus neoliberal no Brasil e a polêmica com Giorgio Agamben

AGAMBEN, Giorgio. Homo sacer: O poder soberano e a vida nua. Belo Horizonte: UFMG, 2004 .

AGAMBEN, Giorgio. Estado de exceção. São Paulo: Boitempo, 2010.

ARAÚJO, Ernesto. 2020. Chegou o Comunvírus. Metapolítica 17. 22.abr.2020. Disponível em: https://www.metapoliticabrasil.com/post/chegou-o-comunav\%C3\%ADrus Acesso em abril de 2020.

BENJAMIN, Walter. Sobre o conceito de História. In: $O$ anjo da história. Belo Horizonte: Autêntica, 2016.

FOUCAULT, Michel. Os Anormais. São Paulo: Martins Fontes, 2010.

FOUCAULT, Michel. Nascimento da Biopolítica. Lisboa: Edições 70, 2018.

GOMES, Ana Suelen Tossige; MATOS, Andityas. O estado de exceção no Brasil republicano. Revista Direito e Práxis, Rio de Janeiro, Vol. o8, N.3, 2017, p. 1760-1787. Disponível em: https://www.e-publicacoes.uerj.br/index.php/revistaceaju/article/view/21373/21383 Acesso em: 30.maio.2020

POSNER, Gerald L.; WARE, John. Mengele: A História completa do Anjo da Morte de Auschwitz. São Paulo: Cultrix, 2019. 